\title{
Autoralidade, grupo e encenação
}

\author{
Rosyane Trotta
}

prática dos grupos teatrais brasileiros tem reivindicado - dos pesquisadores, do poder público, dos patrocinadores - uma atenção especial ao seu modo de produção e criação, como também às suas dicotomias e impasses. Apesar da diversidade infinita em termos de organização e estética, boa parte destes grupos aponta para um projeto artístico composto de três pilares: a criação que conjuga texto e cena na sala de ensaio, a presença do diretor como eixo artístico e organizativo, a continuidade da equipe. Os três elementos grupo, processo e espetáculo - estão historicamente ligados à origem do teatro como arte autônoma, encarregada de encontrar seus próprios materiais, sua própria visão de mundo, seu modo específico de formação.

A possibilidade de trazer transformaçōes teatrais em profundidade se vincula, desde o nascimento da encenação, à formação de uma equipe permanente, entregue a um trabalho regular. Os diretores propõem técnicas corporais a serem coletivamente praticadas, de modo a obter uma disciplina de conjunto e despertar uma ética necessária à descoberta de uma expressão própria e à execução coletiva do ato criador. E a própria função do ator encontra novos paradigmas. $\mathrm{O}$ espetáculo, em sentido moder- no, reúne diversas artes na construção de uma obra única assinada pelo diretor.

$\mathrm{Na}$ primeira metade do século XX, prolonga-se o debate entre dois territórios autorais, dramaturgia e encenação, colocando em oposição o sentido e a forma. A arte recém inventada, diante dos protestos sobre sua excessiva liberdade, ora argumentava que a forma elaborada havia surgido da mais profunda fidelidade ao texto, ora reclamava o direito de empreender uma leitura própria. A delimitação deste novo território se fazia por meio da interdependência e da harmonização entre os diversos elementos cênicos que, deste modo, evidenciavam uma linguagem específica.

Entre o surgimento da encenação e a transformação que levaria o teatro à autonomia reivindicada por Gordon Craig, há um processo de meio século. A permanência do elemento literário como propulsor da encenação alimenta a insurreição artaudiana, na década de 20 , contra o "palco teológico", governado por um criador ausente da cena. O conceito de autoria, na visão de Artaud, deveria ser associado ao discurso cênico e não à palavra escrita, sendo atribuição do encenador: "para mim ninguém tem o direito de se dizer autor, isto é, criador, a não ser aquele a quem cabe o manejamento direto

Rosyane Trotta é pesquisadora e doutoranda do Centro de Letras e Artes da UNI-RIO. 
da cena" (Artaud, 1984, p. 149). Em 1946, Jean Vilar, ao mesmo tempo em que defende a supremacia do texto, reconhece que os encenadores vinham sendo, há três décadas, os verdadeiros criadores teatrais:

Considerando que não há poetas, embora haja tantos autores dramáticos; que a função de dramaturgo não tem sido, nos tempos de hoje, efetivamente assumida; e que, por outro lado, os iniciadores, os técnicos, quero dizer, os diretores, têm ultrapassado, às vezes com felicidade, as fronteiras que uma moral conformista do teatro lhes havia fixado, é a estes últimos que devemos oferecer o papel de dramaturgo, essa tarefa esmagadora; e, uma vez isso admitido, não mais importuná-los nem tentar enfraquecer neles o gosto do absoluto (Vilar, 1963, p. 85).

A luta contra o textocentrismo ganha um novo ingrediente no final dos anos 60 , com as práticas de Jerzy Grotowski. As palavras passam pelo exercício criativo do ator: podendo ser balbuciadas, omitidas, recortadas, elas são matéria, instrumento, e não mais território. Já não se trata de deixar o ator entregue a seus talentos naturais, nem de reproduzir uma realidade proposta pelo texto e nem de executar no palco um desenho criado "em gabinete" pelo encenador. $\mathrm{O}$ ator seria o criador de movimentos e açôes; o corpo, sua gramática. No livro $A$ linguagem $d a$ encenação teatral, Roubine utiliza a expressão "autor coletivo", para caracterizar a especificidade e a transformação que o Teatro Laboratório anuncia para a história do teatro moderno:

$\mathrm{O}$ ator e a coletividade em que ele se insere participam da elaboração do texto. A partir de então, não é mais difícil imaginar uma outra prática, que excluiria a necessidade de recorrer a um texto-pretexto, a um texto anteriormente construído. De então em diante, é o conjunto de todos os que representam o texto que se constitui no seu autor coletivo (Roubine, 1982, p. 66-7).
Se a autoria cênica ganha um novo componente, a função do diretor permanece primordial, tanto para a referência dos princípios estéticos e ideológicos, quanto para a própria concepção da obra (em Akrópolis, por exemplo, um texto que transcorre na catedral de Varsóvia, com personagens do imaginário religioso, transfere-se para um campo de concentração e seus prisioneiros condenados à morte).

Esta "outra prática" a que se refere Roubine se inicia com grupos como o Living Theatre e o Théâtre du Soleil. O campo autoral do diretor e dos atores avança para além do âmbito da interpretação de um texto que, tendo deixado de ser território, deixa de ser também matéria-prima da criação, lugar ocupado agora pela técnica, pela visão de mundo e pelo exercício cênico que se tornam o vocabulário do processo criativo. A área da sala de ensaio se converte em tela vazia, espaço em branco onde se farão os esboços, as rasuras e a elaboração de uma partitura que agrega a um só tempo ação e palavra.

A expressão "escrita cênica", que surge nos anos 70 , reconhece por fim a arte autoral do encenador e o espetáculo como obra autônoma. No verbete de Pavis, a escrita cênica decorre de uma encenação "assumida por um criador que controla o conjunto dos sistemas cênicos, inclusive o texto, e organiza suas interaçōes, de modo que a representação não é o subproduto do texto, mas o fundamento do sentido teatral". (Pavis, 1999:132)

Pode-se dizer que a noção de escrita cênica, que sustenta a autonomia da arte teatral, compreende duas modalidades de estrutura organizativa e de processo de criação do teatro contemporâneo: de um lado, a estrutura piramidal em cujo topo está o diretor que imprime no espaço e no corpo do ator a escrita de uma subjetividade particular; de outro lado, a estrutura circular em que o diretor recolhe o material criado pelos atores e costura a escrita de um alfabeto coletivo. $\mathrm{O}$ "gosto pelo absoluto" e a criação coletiva partilham um mesmo tempo histórico e, em certos casos, um mesmo espaço cênico: 
Vale notar que encenadores como Peter Brook e Ariane Mnouchkine, se dizem grupo e no entanto são fortemente centralizados. Há assim uma esquizofrenia: por um lado a arte suprema destas companhias está na encenação, por outro lado coloca-se em questão a organização teatral e a relação entre as pessoas (Bruno Tackels, em palestra no Itaú Cultural, por acasião do Próximo Ato, São Paulo, novembro de 2006).

Cabe perguntar se esta "esquizofrenia" não constitui intrinsecamente o paradoxo do teatro contemporâneo: valorização do espetáculo como obra assinada por um autor e valorização da originalidade que emerge de um processo coletivo de criação.

\section{A ausência do coletivo}

A configuração da autoria que se ergue sobre estes dois pilares - coletivo e encenação -varia de acordo com cada encenador e cada grupo. Em um extremo, pode-se colocar o ator que fornece material bruto, partituras (físicas, verbais, narrativas) a serem selecionadas e editadas pelo encenador; em outro extremo, o ator participa do projeto em toda a sua extensão, da concepção à composição da obra. Quanto maior a flexibilização das funçôes, maiores os conflitos de que se constitui o processo. Esta obra coletivamente criada tende a ser menos unitária e menos contínua do que os espetáculos em que as individualidades artísticas transitam no terreno seguro de um texto sobre o qual se desenha, antes do início da prática, uma concepção.

Em palestra na Fundação Casa de Mateus, em Lisboa, 1984, sobre as relações entre o texto e a cena, Bernard Dort analisa que, depois de sua deposição, nos anos 70 , o texto volta ao teatro e permanece como elemento integrante de sua linguagem, ocupando diferentes posições de acordo com o sistema teatral em que se inclui. Ele resume sua visão sobre o teatro contemporâneo nos seguintes termos:
(...) para mim, em todo caso, o que interessa hoje no teatro é justamente o modo de relação que se institui entre os elementos relativamente autônomos da representação: o texto, o espaço, a representação do ator, o tempo. (...) A essência do teatro não é que o texto seja representado, mas uma interação de todos os elementos que o constituem, uma espécie de prova por que passam os elementos, uns perante os outros. (...) é um combate entre os diversos elementos que se confrontam e afrontam e de certa maneira entram em conflito (Dort, 1984, p. 133).

Nos processos criativos em que os elementos cênicos, incluindo o texto, permanecem provisórios, o jogo de construção e desconstrução se opera simultaneamente em todas as áreas, não havendo um elemento anteriormente acabado nem criaçôes à margem do percurso coletivo. A função-autor pode parecer fragmentada ou diluída se tomarmos como parâmetro a literatura dramática, comparando um modelo supostamente pleno (a obra fundada por um discurso individual e por isso estilisticamente fechado) a um modelo em que a unidade se perde. No entanto, do ponto de vista da obra-espetáculo, não há diluição e sim pluralidade, e a idéia de compartilhamento parece mais apropriada por comportar dois movimentos: aquele de compartilhar (distribuir) e aquele de compartilhar de (participar de). Aqui o foco não está na obra, mas no processo. A autoria deixa de ser um atributo do sujeito, tornando-se uma ação que mobiliza aqueles que a promovem e se consuma no ato recíproco de fazer, que necessita tanto encontrar o consenso dentro do dissenso quanto permitir o dissenso dentro do consenso. Vem daí o seu sentido político - e, podemos dizer, mais profundamente político do que aquele impresso em formulações verbais ou fabulares da obra acabada.

A distinção entre criação coletiva e processo colaborativo, embora já bastante discutida, merece ser reexaminada. Se, aos olhos de alguns pesquisadores, o processo colaborativo 
parece uma evolução da criação coletiva ${ }^{1}$, esta análise toma como princípio o modelo da especialização, da profissionalização e da racionalização do processo. Também não parece correto afirmar que ambas as modalidades inserem o dramaturgo no processo criativo. ${ }^{2}$ Os dois modelos abrigam distinções que apontam mais para duas concepçóes distintas de teatro do que para a persistência de um modo de criação que se adapta às condiçõos de seu tempo.

A criação coletiva, nos grupos brasileiros dos anos 70, aboliu a função do dramaturgo com o objetivo de fazer do processo de criação cênica a fonte primordial - e, em muitos casos, única - da autoria. Alguns grupos (Asdrúbal Trouxe o Trombone, Navegando, Pão\&Circo, Jaz-o-coração) a utilizaram em determinados espetáculos, enquanto outros (Pod Minoga, Diz-ritmia, Manhas e Manias, Contadores de Histórias) fizeram deste processo o elemento definidor de sua linha de trabalho. A direção esteve sempre presente nas fichas técnicas, com exceção do grupo Pod Minoga, que suprimiu também esta função, juntamente com todas as demais, e assinava unicamente o nome do grupo em "criação coletiva". É curioso notar, no caso do Asdrúbal, o modo como os créditos mudam ao longo de sua trajetória. Nos primeiros espetáculos, que são, mais que releituras, trituraçôes de um texto de base, o crédito ao grupo é feito na função "adaptação". Na segunda fase, utiliza-se o termo criação coletiva creditado, com "direção e texto final" assinados por Hamilton Vaz Pereira. No último espetáculo, quando alguns dos integrantes antigos são substituídos, o diretor assina "concepção, roteiro e direção” e já não há crédito autoral para o grupo.
Os processos colaborativos, embora estejam associados à pratica de um teatro contínuo, geralmente ligada ao trabalho de um grupo ou companhia, não se constitui como expressão de uma identidade comum, mas como contraposição e justaposição de diversidades individuais em que o elo comum e o fio condutor é o espetáculo. Na criação coletiva, o grupo em geral é anterior ao projeto, já está reunido quando trata de se colocar a pergunta "o que faremos", ao passo que os espetáculos produzidos em processo colaborativo nascem de um projeto pessoal do diretor, que reúne a partir de então a equipe de que necessita para empreender a criação. Cabe perguntar se a poética do processo colaborativo vem conseguindo efetivamente negar o "ator-linha-de-montagem" (Araújo, 2002, p. 42), e transformá-lo em sujeito, se a funçãoautor tem tido condições de se formar na prática daqueles que nomeiam colaborativo o processo que empreendem.

Um grupo instaura e sofre a contradição entre os valores que cultiva entre si - e que pretende afirmar artisticamente - e os valores socialmente aceitos - em relação aos quais ele pretende se contrapor. Evidentemente os valores sociais estão dentro do grupo, ainda que como via negativa de onde ele tira a motivação que o empurra para fora, para fincar sua bandeira fora de si. Lá onde se cultivam valores que ele recusa é também onde ele imagina encontrar seus pares, o público cúmplice que poderá acompanhálo, partilhando de suas obras. A tensão entre o "dentro" e o "fora" do grupo podem ser sua principal ferramenta no desafio de escapar, pela transgressão, de modelos estéticos.

A constituição de um grupo que, com a experiência de diversos processos, tem a opor-

1 Stela Fischer, em sua dissertação, fala sobre "o avanço do coletivo para o colaborativo" (2003, p. 55).

2 Adélia Nicolete escreve que em ambos os procedimentos "o dramaturgo desceu, finalmente, de sua torre de marfim e foi para a sala de ensaio" (2002, p. 319). No entanto, nas fichas técnicas dos espetáculos em que o termo "criação coletiva" aparece, não há a função de dramaturgo. 
tunidade de amadurecer suas relações pessoais e artísticas e sua intimidade criativa, se apresenta como um terreno propício ao exercício da autoria coletiva. No entanto, o conceito de grupo sofreu substancial transformação nas últimas décadas. A palavra, que na década de 70 identificava um coletivo definido por uma ideologia (ou, no mínimo, pela afinidade de gosto) e pela continuidade da maioria dos integrantes, se refere, trinta anos depois, não mais à reunião de determinados artistas, mas ao diretor e à concepção de teatro que ele desenvolve em uma mesma linha de projetos de encenação. Nesta acepção, grupo é definido como "núcleo artístico estável”. Núcleo, que significa ponto central e parte proporcionalmente minoritária do todo, difere enormemente da idéia de coletivo. A palavra núcleo dimensiona uma estrutura em que uma minoria concebe, realiza e mantém a continuidade do projeto, enquanto os convidados, que representam a maioria, entram no esquema do trabalho avulso. Não é difícil deduzir que a esta nova configuração de grupo corresponde uma também nova configuração da autoria.

O centro nervoso do processo de criação cênica se localiza nas funções de direção, atuação e dramaturgia, embora outras funções possam participar do percurso. Podemos considerar que quanto menor a afinidade e a experiência do coletivo, maior a necessidade de centralização do processo na figura do diretor. Em outras palavras, quanto mais efetivos os elos que ligam os integrantes ao grupo e sua proposta principalmente no que diz respeito a um entendimento comum da concepção que se coloca em prática e a um vocabulário cênico gerado por experiências anteriores - maior a possibilidade de autonomia destes artistas. Neste sen- tido, o coletivo não se instaura pela simples reunião de indivíduos dedicados a um mesmo projeto, mas depende da construção de uma "cultura de grupo" 3 baseada em uma subjetividade coletiva.

A criação coletiva, embora tenha emergido de um contexto histórico específico, não se restringe ao passado, sendo praticada ainda hoje por grupos cujos integrantes se responsabilizam não apenas pela cena, mas pelo projeto e sua continuidade. Nestes grupos - entre os quais podemos citar a Tribo de Atuadores Oi Nóis Aqui Traveiz (RS) e o Grupo Pedras (RJ) - os atores se ocupam tanto das questôes cênicas quanto extra-cênicas - produção, distribuição, divulgação. Pode-se considerar que a qualidade de engajamento e a continuidade necessárias a esta modalidade teatral exigem uma relação estreita entre o teatro que se pratica e os valores que orientam a vida pessoal do artista. Talvez por isso sua presença esparsa no cenário mundial. Entrevistas ${ }^{4}$ com diretores e atores de grupos mostram duas variaçóes de resposta para a origem desta ausência: de um lado, os atores apontam a tendência de centralização do diretor em relação a todas as opções que dizem respeito à obra, informando que a função do diálogo não abrigaria de fato uma instância decisória, mas apenas uma espécie de ouvidoria; de outro lado, os diretores apontam a tendência de alienação do ator em relação a todas as instâncias que fogem ao âmbito do personagem e de seu espaço na obra. O efeito daquilo que chamamos "ausência do coletivo" sobre o processo colaborativo produz uma configuração da autoria muito distinta daquela encontrada na criação coletiva, uma vez que, pela falta de identidade entre os participantes, recai sobre o encenador a tarefa de "fabricar" o coletivo autor.

3 Termo empregado por Ferdinando Taviani para definir o trabalho do Odin Theater.

4 A autora vem realizando pesquisa para uma tese de doutorado sobre a autoria coletiva no processo de criação teatral. 
Deste ponto de vista, o processo colaborativo seria uma modalidade que procura conjugar ao mesmo tempo individualismo e pluralidade, e sua principal utopia estaria expressa no papel preponderante conferido ao diálogo entre os sujeitos, na tentativa de exercitar o consenso na ausência de condições propícias para gerar uma identidade coletiva. Não será por acaso que o processo de criação que conjuga texto e cena, hoje disseminado entre os mais diversos grupamentos teatrais (mesmo entre aqueles que não pretendem ser ou se tornar grupo), se baseie algumas vezes no conceito de performance. $\mathrm{O}$ performer individualiza a criação, como autor-ator-encenador que é em si mesmo o espetáculo. O diretor Fábio Ferreira, por exemplo, fala sobre o processo do espetáculo Discursos: ${ }^{5}$

Existiu desde o início um desejo meu de trabalhar com material de seleção individual e subjetiva, para tornar a cena um lugar de "propriedade e intimidade" de cada um dos atores e de todos. Depois, durante os ensaios existiu muito espaço para proposições de cena, com abertura plena para "estilos" e "soluções" particulares. (...) Não chegamos a uma perfor- mance, mas lidamos com fatos e composições da performance e da dança contemporânea ${ }^{6}$

Assim, o processo que parte da noção de performance para a construção da dramaturgia, minimiza o problema da falta de identidade coletiva fazendo o trajeto oposto, ou seja, partindo do indivíduo ("de cada um") para criar um ambiente ("de todos"). Este trajeto deixa a configuração do todo a cargo do trabalho do diretor, sem que haja necessidade de um entendimento coletivo sobre a linguagem, a narrativa, a abordagem. Pode-se perguntar se ainda cabe falar de um "ator-autor", na medida em que ele é convidado a participar de uma experiência pré-definida na qual, tendo liberdade para criar seus próprios textos e cenas, permanece dentro de um território individual, sem atingir o âmbito do espetáculo.

Para sintetizar as características constitutivas das duas modalidades em um quadro comparativo, tomamos por base o processo colaborativo tal como é descrito e definido na dissertação de Antônio Araújo sobre a Trilogia Bíblica e a criação coletiva praticada pelo grupo Oi Nóis Aqui Traveis, de Porto Alegre.

5 Estréia no Sesc Copacabana, Rio de Janeiro, 2005, com direção de Fabio Ferreira. O espetáculo Discursos se estrutura em solos independentes, de que participam eventualmente os demais atores para a composição da cena.

6 Depoimento à autora, Rio de Janeiro, 29 de agosto de 2005. 


\section{Criação Coletiva}

O texto não existe antes do processo

Os atores e o diretor elaboram em conjunto a concepção, a construção e a produção do espetáculo

Elimina-se o autor dramático como função específica e especializada

O ponto de partida para a experimentação cênica é a proposta criada pelo grupo

O texto emerge da cena

As escolhas ligadas ao texto cabem aos atores e ao diretor

Texto e cena são instâncias indissociáveis

O grupo se forma por afinidade entre os participantes e as funções se estabelecem no processo Campo autoral coletivo, unidade

\section{Encenação e autoralidade}

Em La Représentation Émancipée, 1988, Bernard Dort identifica o surgimento de uma nova concepção de representação que, baseada na autonomia dos criadores do espetáculo, "não postula mais uma fusão ou uma união entre as artes" (Dort, 1988: 181). O teatro contemporâneo consistiria na interação - ou mesmo na rivalidade, como escreve Dort - entre os sistemas significantes que o compõem. Constatando, na década de 80 , "a renúncia a uma unidade orgânica prescrita a priori” - e à caixa mágica que contém uma totalidade - Dort defende uma crítica a Wagner e a Craig, por "uma nova definição de representação teatral que, em lugar de fazer uma articulação estática de signos ou um

\section{Processo Colaborativo}

O texto não existe antes do processo

Os atores participam da construção do espetáculo

Insere-se o escritor no processo de criação, como função específica e especializada

O ponto de partida para a experimentação cênica e para a criação do texto é o projeto apresentado pelo encenador

O texto é construído em diálogo com a cena

As escolhas ligadas ao texto cabem ao escritor

Cabe ao diretor e ao escritor estabelecer a forma como se opera o diálogo entre o texto e a cena

O grupo se forma por afinidade com o projeto, cada integrante tendo sido convidado pelo diretor a ocupar determinada função

Campo autoral plural, hibridismo

meta-texto, a enfocaria como um processo dinâmico que ocorre no tempo e é efetivamente produzido pelo ator." (p.177/178)

A criação em processo coletivo contestaria a própria noção de linguagem, libertando o teatro da concepção totalitária por meio da qual o encenador estabelecera um outro "palco teológico", em que o conceito antecede a experiência. $\mathrm{O}$ encenador deixa de solicitar ao ator que destine suas habilidades a uma concepção artística elaborada fora de seu corpo, rompendo com um sistema teatral inaugurado há um século e lentamente implantado ao longo da primeira metade do século XX. A passagem da encenação moderna ao que Bernard Dort chamou de "representação emancipada" - ou, do ponto de vista do processo, a passagem da centralização para a pluralização da autoria - pode 
ser identificada como a abertura das diversas áreas do espetáculo à subjetividade de seus respectivos criadores. A partir desta reflexão, podemos identificar três aspectos da configuração da autoria na criação teatral:

1) A dinâmica entre concepção e processo: relação entre a criação que vem do "espaço público" do ensaio e a criação que, ocorrendo em um espaço reservado, antecipa-se à primeira. De um lado, a concepção que antecede o processo; de outro, a concepção que emerge do processo.

2) A dinâmica entre as funçôes: de um lado a centralização do encenador; de outro, a autonomia nas funções.

3) A relação que os elementos cênicos estabelecem entre si, caminhando para a pluralidade ou para a unificação.

A princípio, os três aspectos se agrupariam em duas vertentes: a primeira, reunindo anterioridade da concepção em relação ao processo, centralização autoral do encenador e unidade de linguagem; a segunda comportaria a anterioridade do processo em relação à concepção, a autonomia das funções e a pluralidade de sentido e forma. A encenação, histórica e esteticamente assimilada, liberta-se de si mesma e pode ser tomada pelos demais artistas-autores. No entanto, pluralidade não significa coletivização - talvez, muito pelo contrário, seja o indicativo de uma individualização da autoralidade teatral - e nem sempre indica uma valorização do processo coletivo como fonte de criação.

Nas práticas teatrais em que o percurso que conduz ao espetáculo já não consiste na realização de um texto e uma linguagem previamente definidos, em que a sala de ensaio se torna o lugar onde se engendra o projeto, o fazer teatral resulta do diálogo da equipe consigo mesma e a concepção se detém sobre o processo. A função do encenador sofre uma transformação paradigmática, uma vez que já não se trata da competência de realização de uma idéia, da fisicalização de uma linguagem, mas da fun- dação das formas e das relações de criação. Ele não pode mais ser comparado ao pintor que assina o quadro: ele está diante do espaço vazio e da necessidade de conceber a gênese da autoria, de promover a apropriação dos meios de produção da subjetividade, individual e coletivamente. Sua concepção se refere, antes de tudo, à função que ele confere a si próprio e aos demais: como configura o coletivo, como coloca em relação os diversos autores, através de que caminhos deflagra a autoralidade.

Se na modernidade admite-se que o sujeito, ao invés de determinar as relações, é justamente por elas definido, também a função do ator se forma na dinâmica do processo. A possibilidade de reconhecer em um grupo a presença da categoria de "ator-autor" não está ligada à existência prévia ou não de um texto, à presença ou não do dramaturgo na sala de ensaio, mas à concepção do teatro como lugar de uma pluralidade autoral, à renúncia ao espetáculo como unidade forjada por uma função singular.

A noção de espetáculo como unidade corresponde a uma configuração piramidal da autoralidade. No topo está o autor do espetáculo, função que concentra a concepção da obra e centraliza as relaçóes chamando para si cada elemento e cada criador, que mantém com ele um diálogo privado e exclusivo. A noção de pluralidade, ao contrário, postula a autonomia dos discursos artísticos, sem que haja predomínio de um elemento sobre os demais: o encenador, ao invés de soldar os elementos em uma unidade de estilo e um sentido comum, promove o afastamento entre eles.

A autoria coletiva, ao contrário, se configura por meio do constante e quase exaustivo diálogo coletivo que, se não forma necessariamente um sentido unificador, promove a mútua interferência e mútua contaminação entre os autores. $\mathrm{O}$ encenador não toma para si a exclusividade de interlocução das demais funções artísticas mas, ao contrário, coloca em circulação as diversas subjetividades. Nas três concepções, portanto, o diretor desempenha um papel fundamental, embora distinto. 
A terceira via de configuração da autoria toma a pluralidade não como objetivo, mas como ponto de partida, matéria-prima para o diálogo e o conflito das diferenças. Neste tipo de processo, a autoralidade avança além dos territórios individuais que produzem fragmentos criativos a serem inseridos na obra: ela se projeta no espaço que se estabelece como território existencial coletivo. A concepção sai da privacidade para o espaço público da sala. Se ao "euautor" plural vem se reunir um "nós-autores", pode-se falar então em produção de uma subjetividade, fonte para a coletivização da autoria.

Neste caso, ao invés da "esquizofrenia" apontada por Bruno Tackels, talvez se possa falar em hibridismo, como no exemplo da Cia dos Atores (RJ), em que, no campo das decisōes artísticas, "ora as escolhas são totalmente do diretor, ora são coletivas" (Santos, 2004, p. 58). O diretor Enrique Diaz, ao se referir ao modo de criação do grupo, considera que os atores são ghosts directors, uma vez que...

em todos os espetáculos há sempre uma ou mais proposições estéticas que são lançadas como enigmas e que são seguidas de uma busca incessante de verificaçōes, raciocínios, questionamentos, novos materiais, dúvidas e conclusōes, sempre feitas em grupo (Enrique Diaz, programa do espetáculo Melodrama, Centro Cultural Banco do Brasil, Rio de Janeiro, 1995).

A noção de autoralidade nasce em função do processo criativo, quando já não se necessita lutar pela autonomia do teatro em relação à literatura, quando o encenador foi liberado de delimitar o seu território em uma autoria individual. As três concepçôes de autoralidade como unidade, como pluralidade e como coletivização - divergem estética e eticamente. Teoricamente, o teatro de grupo seria a modalidade organizativa mais propícia ao exercício de um modo coletivo de criação, mas apenas se admitirmos que o conceito "grupo" tem uma motivação político-existencial que antecede a obra e se instaura na fundação do coletivo-autor, passando inevitavelmente pelo modo como o diretor e os atores exercem suas funçôes. 


\section{Referências bibliográficas}

ARAÚJO, A. Trilogia bíblica. Dissertação (Mestrado). São Paulo: Universidade de São Paulo, 2002.

ARTAUD, A. O teatro e seu duplo. São Paulo: Max Limonad, 1984.

DERRIDA, J. A escritura e a diferença. São Paulo: Perspectiva, 1995.

DORT, B. La représentation émancipée. Paris: Actes Sud, 1988.

"Palestra realizada em 27 de abril de 1984 na Fundação Casa de Mateus". In: O texto e o acto: 32 anos de teatro (1968-2000). Lisboa: Fundação Calouste Gulbenkian/Serviço de BelasArtes, 1984.

FISCHER, S. R. Processo colaborativo: experiências de companhias teatrais brasileiras nos anos 90. Dissertação (Mestrado). Campinas: Instituto de Arte da Universidade Estadual de Campinas, 2003.

FOUCAULT, M. O que é um autor. Cascais: Vega-Passagens, 1992.

NICOLETE, A. "Criação coletiva e processo colaborativo: algumas semelhanças e diferenças no trabalho dramatúrgico". In: Sala Preta, Revista do departamento de artes cênicas, São Paulo: Eca/USP, 2002.

PAVIS, P. Dicionário de teatro. São Paulo: Perspectiva, 2001.

ROUBINE, J.-J. A Linguagem da Encenação Teatral 1880-1980. Rio de Janeiro: Zahar, 1982.

SANTOS, F. C. dos. Processos criativos da Cia dos Atores. Dissertação (Mestrado). Centro de Letras e Artes, UNI-RIO, 2004.

VILAR, J. De la tradition théâtrale. Paris: Gallimard, 1963. 